\title{
INTERACCIONES DEL ARTE ESPANOOL E IBEROAMERICANO
}

\author{
Ana María Fernández García \\ Universidad de Oviedo. España.
}

El estudio de las relaciones económicas, sociales, culturales y artísticas entre España y América ha producido ríos de tinta en las inmediaciones del Quinto Centenario. Obras generales y monografias han ahondado en la investigación de las mutuas influencias e interferencias entre la península y el nuevo continente. En el campo artístico los estudios se han dirigido de forma prioritaria a la etapa colonial, periodo en el que por razón de lazos políticos la dependencia, aunque no directa, sí fue determinante. La laxitud de estos lazos después de la independencia no produjo sin embargo una completa desvinculación del arte español y del americano. Precisamente este escrito pretende estudiar algunas facetas de esta relación postindependiente, centrada en las Bellas Artes. Para ello se analizará la vinculación de las Academias iberoamericanas con artistas peninsulares o con San Fernando; la emigración de pintores, escultores y arquitectos al otro continente hasta 1930; y la celebración de exposiciones colectivas e individuales de signo español en toda América. Estos factores se relacionan en varios países con la masiva presencia de emigrantes y con un cierto resurgir de la hispanidad en el plano cultural.

Por la imposibilidad de abarcar en estas páginas todo el devenir del arte del continente americano, se han seleccionado los ejemplos mejicano, cubano, argentino y chileno, como modelos o patrones de las interacciones entre España e Iberoamérica en el plano artístico. 


\section{ESPANA Y LAS INSTITUCIONES DOCENTES DE AMERICA.}

Todas las Academias de Bellas Artes americanas nacieron para evitar el inconveniente del traslado a Europa a fin de recibir la formación artística oportuna y para permitir un control directo de la calidad de las obras, al margen de la censura eficaz de la Academia de San Fernando. No obstante, fue el centro madrileño el patrón al que se remitieron las instituciones docentes establecidas en toda América, y muchos compatriotas colaboraron en su establecimiento. Incluso en el caso de instituciones tardías, en las que el peso de lo español pudiese ser menos estrecho, creadores nacionales se imbricaron en un determinados momentos en su desarrollo, originando incluso un sesgo estético hacia lo hispánico.

Durante el siglo XVIII el reformismo borbónico y las ideas ilustradas favorecieron la implantación de academias en el continente americano. La primera institución fue la de San Carlos en Nueva España fundada en 1783. Pese a una inicial desaprobación por parte de ciertos académicos de San Fernando, la nueva institución salió adelante gracias a la labor de grabador español Jerónimo Antonio Gil, cuya actividad en Méjico se relacionaba con la política ilustrada de fomento de las artes gráficas, de gran utilidad para el apoyo de las reformas, pues era la base para realizar cartas geográficas o urbanas o la acunación de moneda. Jerónimo Antonio Gil, formado en San Fernando de Madrid, y que en 1778 había viajado a Nueva España para formar una escuela de grabadores en la Casa de Moneda, dio forma al primer proyecto de escuela general de Bellas Artes en la América española '. La aprobación de San Carlos el 25 de diciembre de 1783 mediante Real Orden de Carlos III conllevó el traslado de profesores desde la península y del material didáctico necesario. Tres años después viajaron a ultramar Ginés de Andrés y Aguirre, Cosme Acuña y Antonio González Velázquez. En 1791 hizo lo propio el valenciano Manuel Tolsá y poco después Manuel Ximeno ${ }^{2}$. Todos ellos, dirigidos por un polémico Gil, hicieron realidad el proyecto docente ilustrado, ayudados de material didáctico solicitado a San Fernando: vaciados de esculturas clásicas, copias de pinturas antiguas, tratados españoles, como el de Butrón, Pacheco o Palomino, además de la colección de casi un centenar de obras procedentes de los conventos de jesuitas expulsados ${ }^{3}$. Además de prolongar los métodos y medios habituales de San Fernando, y de contar entre sus profesores con ex-alumnos de la institución madrileña, las relaciones en una y otra academia, no siempre muy cálidas, cuajaron en 1792 con la creación de becas para estudiantes mejicanos que estudiarían en San Fernando durante seis años bajo al supervisión de Cosme Acuña. Las estancias de perfeccionamiento en Madrid no tuvieron el éxito que cabría esperar, debido sin duda a la enemistad manifiesta entre Acuña y los profesores de 
San Carlos ${ }^{4}$. Las becas fueron escasas y problemáticas por lo que se frustró una iniciativa interesante que contribuiría a afianzar las relaciones entre la academia de San Fernando y la ya emancipada de San Carlos.

En Cuba, ya en el siglo XIX, y a imitación de San Carlos se fundó en 1818 la Academia de San Alejandro de La Habana. Nació por el patrocinio de la Sociedad Económica de Amigos del País, que desde fines del siglo XVIII había mantenido una escuela gratuita de dibujo y pintura. Funcionó al principio como un mero centro de enseñanza mecánica de dibujo y escultura, siempre dirigido por artistas extranjeros en la isla, desde el francés Vermay hasta el escultor español Augusto Ferrán. En 1841 dos arquitectos españoles afincados en la isla solicitaron a San Fernando la creación de una escuela de arquitectura, dirigida a maestros de obras en activo, para paliar la carencia de formación teórica en matemáticas y dibujo 5 . Así, aunque el proceso de gestación de las instituciones docentes cubanas no estuvo dirigido por artistas españoles, sí fue aprobado y fomentado desde la península y varios plásticas nacionales se integraron en la plantilla del personal docente.

Tanto en el caso mejicano como en el cubano la dependencia entre San Fernando y las academias americanas se hizo realidad en la inevitable dependencia burocrática que agilizó o pospuso su creación, en la política sancionadora de la institución madrileña en las obras del nuevo continente ${ }^{6}$ y en la propuesta de métodos docentes semejantes en los dos lados del océano. También artistas establecidos en ambos territorios potenciaron de una u otra manera la creación y sostenimiento de las instituciones, por otra parte necesitadas de personal docente. La plantilla docente de origen español no se redujo únicamente al periodo colonial, sino que después de lograda la independencia continuó siendo una de las principales fuentes del personal. Un ejemplo en este sentido fue la llegada en 1846 a Méjico del nazareno catalán Pelegrín Clavé. Fue él quien reorganizó las clases de pintura de San Carlos y recuperó la temática religiosa, relegada a un segundo plano después de la independencia?.

Un decisivo papel en la Academia de Bellas Artes de Santiago de Chile tuvo el pintor gallego Fernando Álvarez de Sotomayor ya en este siglo. Viajó en 1908 a la capital chilena como profesor de colorido y composición, pasando en 1911 a desempeñar el cargo de director, hasta su regreso a la península en 1915. Durante su estancia sudamericana Sotomayor revolucionó los hábitos pictóricos de aquel país, profundamente arraigados en la estética de raíz francesa, para proponer un tipo de pintura costumbrista, perfecta descriptora de tipos humanos y ambientes, dentro de esa vertiente hispánica del regionalismo de principios de siglo. La llamada "Generación de 1913" fue la consecuencia directa de su estancia chilena. Arturo Gordon, 
Pedro Luna, Alfredo Lobos o Ezequiel Plaza supusieron la aceptación del género costumbrista, de raigambre hispana, enlazado por la estética del Siglo de Oro, con Zurbarán y Velázquez, y alejado del refinamiento afrancesado ${ }^{8}$. Precisamente en Chile la influencia de la estética española había sido muy reducida durante el siglo XIX, pues artistas de otras procedencias, como los franceses Ernesto Charton y Auguste Monvoisin o los ingleses Charles Wood - Tomas Somercales, habían monopolizado la producción artística en el país sudamericano, claramente seducido por los cantos de sirena de la plástica gala. Sotomayor truncó esa tendencia pues desde su privilegiado puesto en la Academia descubrió los derroteros del arte español, que en la generación de sus discípulos se convirtió en el modelo o referente estético?

También en la Academia de Santiago desarrolló su labor docente el escultor y pintor barcelonés Antonio Coll y Pi (1857-1943), llegado a la capital chilena en 1906, contratado por el Gobierno para desempeñar el cargo de profesor de Dibujo Ornamental y Pintura Decorativa. Poco después se hizo cargo de la materia de modelado en la Escuela de Arquitectura. Su larga permanencia en Chile cuajó en la realización de los monumentos a Ercilla y a los Bomberos en Santiago, así como los relieves del Palacio de Justicia y del Museo Nacional de Bellas Artes ${ }^{10}$. Desde luego la llegada prácticamente coetánea a Chile de dos españoles para desempeñar cargos docentes en un país tradicionalmente despegado de la estética peninsular, ejemplifica la tendencia favorable hacia lo hispánico general en toda América en el cambio de siglo.

En el campo de la docencia particular, desvinculada de las academias oficiales, varios artistas españoles jugaron un papel importante en la segunda mitad del siglo XIX. Quizás los ejemplos más preclaros en este sentido provengan del caso argentino, donde la pléyade de pintores y escultores llegado en el cambio de siglo propiciaron la apertura de escuelas privadas, además de patrocinar la creación de instituciones docentes en ciudades de provincias. Una iniciativa interesante en este sentido fue la fundación del grupo $L a$ Colmena Artística en Buenos Aires, tertulia integrada por artistas, músicos y literatos prioritariamente de origen peninsular. Organizó una academia libre, en la cual una modelo servía de referencia a los jóvenes estudiantes de pintura o escultura, dirigidos por un veterano pintor español, ya fuese Nicolau Cotanda, el asturiano Arango o Cao. Al margen de estas actividades docentes, La Colmena Artística aglutinó a las personalidades creativas emigrantes y celebró ocasionales exposiciones de obras, como el Primer Salón de Humoristas del Plata en 1896, donde se dio cita lo mejor de la caricatura europea en Buenos Aires". 


\section{LOS ARTISTAS ESPANOLES EN AMERICA DESPUES DE LA INDEPENDENCIA.}

Desde los primeros momentos de la colonización de América, viajaron a ultramar maestros de obras, pintores, talladores y orfebres. El puerto de Sevilla se erigió en el centro del comercio hacia América y fueron muchos los artistas que se asentaron alli a la espera del momento para cruzar el océano. El trasvase humano artístico fue especialmente importante en los territorios de Nueva España o Perú. Los creadores eran requeridos para la fundación de nuevas ciudades, la construcción de edificios representativos del poder colonial, la decoración y erección de templos y la difusión iconográfica de los dogmas de la religión católica. En ausencia de artistas indígenas para estos menesteres, profesionales y monjes aficionados llevaron a ultramar un arte español que pronto se fundió con la estética precolombina y con las tendencias europeas llegadas a América mediante grabados. Durante la etapa colonial, la pintura tuvo el papel más señalado pues facilitaba la difusión de un ideario religioso dirigido a una población heterogénea, de creencias arraigadas y lenguas diferentes. La pintura tuvo, en este sentido, un carácter didáctico, destinado a abolir la idolatría, y fue utilizada así especialmente por las ordenes religiosas: "... algunos usaron un modo de predicar muy provechoso para los indios, conforme al uso que ellos tenian de tratar todas sus cosas por pinturas. $Y$ era de esta manera: hacian pintar en un lienzo los artículos de la fe, en otro los diez mandamientos, en otro los siete sacramentos, y lo demás de la doctrina cristiana. Y cuando el predicador quería predicar los mandamientos, colgaba el lienzo ... de manera que con una vara de las que traen los alguaciles pudiese ir señalando la parte que quería" ${ }^{12}$.

El grupo de artistas españoles emigrados durante el periodo colonial, no siempre conocido, abarcó profesionales y aficionados dedicados de forma prácticamente exclusiva al arte oficial y al religioso, tanto en el campo de la arquitectura como en el de las artes plásticas. Los retratos de monarcas, virreyes y miembros destacados de la sociedad novohispana junto con la iconografía sacra destinada a iglesias y monasterios y algún que otro encargo particular del mismo género monopolizaron la actividad de los pintores españoles emigrados a América.

Con la independencia el flujo migratorio de artistas a ultramar menguó considerablemente. El clima de rechazo hacia lo español generado con la emancipación no favorecía la presencia de creadores peninsulares en aquellas tierras, excepto los que viajaron por expreso requerimiento de Academias oficiales, como Pelegrín Clavé. Sí en cambio se radicaron en todos los países iberoamericanos artistas europeos de otras procedencias, fundamentalmente norteamericanos en el caso mejicano e ingleses o franceses en el cono sur. 
Sólo Cuba mantuvo un presencia sistemática de españoles dedicados a actividades artísticas hasta 1898 , fecha en que la afluencia no se cortó como en otros casos sino que se mantuvo con la misma intensidad de antaño.

Es interesante definir lo que los geógrafos denominan como "factores de expulsión" y "factores de atracción", esto es, los mecanismos que favorecieron el traslado de los artistas a ultramar. Ciertamente la saturación del mercado español del siglo XIX, condicionado por premios y galardones en los certámenes oficiales, y la poca consistencia de la inversión artística privada hacían que el panorama profesional de muchos de los pintores o escultores no fuese todo lo halagüeño que cabría esperar. Por otra parte en América la existencia de una fortísima colonia de inmigrantes, a la vez clientes y valedores de la plástica peninsular, así como el creciente consumo suntuario en las capitales americanas atraía a los artistas españoles hacia la aventura americana ${ }^{13}$.

El ciclo de la emigración artística española después de la independencia registra un despegue importante a partir de la segunda mitad del siglo XIX, coincidiendo en los países del cono sur con la máxima afluencia de emigración general entre 1880 y 1930. Durante estos cincuenta años, e integrados en los intensos flujos migratorios procedentes de la península viajaron a América pintores, escultores, arquitectos y grabadores, que dejaban atrás una vida profesional generalmente mediocre a la espera de mejores éxitos artísticos en aquella tierra de promisión. Artistas gallegos, catalanes, vascos y asturianos constituyeron el núcleo más importante de emigración; regionalidades que por otra parte constituían el grueso de la migración transoceánica.

La dedicación primordial de los pintores emigrados fueron los géneros correspondientes a una sociedad burguesa en ascenso: el retrato, el taubletin, la pintura costumbrista, la ilustración gráfica y ocasionalmente la decoración de interiores. El retrato gozó de continuidad con respecto a la etapa colonial, y era un tipo de pintura requerido por amplios sectores de la burguesía en alza que reclamaba un género anteriormente reservado a la nobleza. También las instituciones legitimaron y emblematizaron su pasado mediante el encargo de efigies de presidentes, miembros destacados o personajes de su pasado. Hubo en este sentido varios intentos de crear iconotecas en centros regionales, contando siempre con el auxilio de artistas connacionales, como la del Centro Asturiano de La Habana ${ }^{14}$, la del Club Español de Buenos Aires o la del Laurak Bat de la misma capital.

El "taubletin" y la escena de costumbres son géneros netamente burgueses, que al mismo tiempos que lograban éxito en América hacían lo propio en todo el mercado mundial. La veta goyista y al pintura de casacón, por su carácter poco complejo, su carga de decorativismo se ajustaba a los reque- 
rimientos de una sociedad nueva que olvidaba la grandilocuencia de la pintura de historia, de las alegorías clásicas y de la pintura religiosa.

El dibujo y la colaboración en revistas ilustradas fue una de las actividades más habituales de los artistas españoles afincados en América. Muy singular fue el caso del bilbaíno Víctor Patricio de Landaluce, radicado en La Habana a mediados del pasado siglo, ilustrador de libros y colaborador habitual de los semanarios satíricos El Moro Muza y La Charanga. En tales publicaciones Landaluce mostraba un desprecio absoluto hacia los ideales de emancipación en la isla, y su obra se ha considerado posteriormente como un afrenta al sentimiento nacional cubano ${ }^{15}$. En Argentina y Uruguay El Padre Españoh Caras y Caretas, Don Quijote o Plus Ultra, fueron algunas de las revistas ilustradas más claramente vinculadas con la colonia de dibujantes radicados en la ciudad ${ }^{16}$.

La clientela de los artistas español emigrados a América abarcaba de forma prioritaria a los inmigrantes enriquecidos de idéntica procedencia nacional, que encontraban en la posesión de obras de arte español un elemento más a apego a la tierra de origen, de definición de su propia idiosincrasia nacional. Los retratos de Álvarez Insúa o Joaquín Ruiz, realizados por Manuel Angel en la década de los ochenta en La Habana, o las efigies de empresarios gallegos realizados en Buenos Aires por Vila i Prades así como los innumerables paisajes gallegos, asturianos o catalanes confirman este extremo. Desde luego la clientela segregada de las capas de inmigrantes prefería aquellas obras que por temática, ejecución y firma reconfirmase la identidad nacional del adquirente, y distinguiese sus hábitos de los de otros grupos étnicos. También los centros regionales de cada ciudad encargaron obras a sus coetáneos. En este sentido, destacan las escenas realizadas por Mariano Miguel González en el salón de fiestas del Centro Asturiano de La Habana ${ }^{17}$, o la iconoteca de retratos de presidentes del Club Español de Buenos Aires llevada a cabo por varios artistas peninsulares radicados en la capital porteña.

Las instituciones relacionadas con la emigración peninsular, fuesen centros regionales de carácter mutual o recreativo o bien entidades bancarias o empresariales también jugaron un papel primordial en el fomento de la actividad de sus compatriotas artistas, manteniendo esa voluntad de afianzamiento de lazos nacionales común en otros aspectos económicos o sociales. Así, estos organismos además de encargar obra a título individual o institucional, organizaron muestras pictóricas que las que se reunía lo mejor del acervo plástico nacional en América. La sede del Diario de la Marina en La Habana, el Club Español de Buenos Aires y Méjico, y los centros regionales -en especial en Centro Gallego de Chile - se convirtieron esporádicamente en centros expositivos del arte español emigrado. 
Otra de las singularidades de la emigración artística a América fue su tendencia a coligarse en instituciones de signo español, ya fuesen centros regionales o asociaciones de pintores y escultores creadas al efecto, como $\mathrm{La}$ Colmena Artistica de Buenos Aires. Un simple repaso a las listas de socios de los instituciones regionales demuestra la vinculación de los plásticos con su colectividad de origen. Precisamente para las sedes de estos organismos trabajaban pintores en la decoración, escultores en las labores de relieve - generalmente enaltecedoras del pasado patrio o regional- y arquitectos espańoles en la realización de las trazas. Algunas individualidades empero se integraron que tal forma en el ambiente social y cultural de adopción que solicitaron la ciudadanía, aunque nunca llegaron a desvincularse totalmente de su origen, participando en las Exposiciones Nacionales de Madrid e indistintamente en los salones oficiales de cada país americano.

La última peculiaridad general de la emigración artística trasoceánica fue la preferencia por el asentamiento en las capitales o grandes ciudades. Precisamente en aquellas urbes en crecimiento existía una burguesía asentada económicamente capaz de requerir y gustar de objetos suntuarios. Los agentes comerciales y los mecanismo de difusión artística se encontraban también en los núcleos de población importantes, por lo que hasta este siglo se impuso la radicación en las capitales, donde también se daban cita los más nutridos sectores de la emigración espanola.

\section{LA OBRA EMIGRADA. LAS EXPOSICIONES DE ARTE ESPANOL EN AMÉRICA.}

No cabe duda que las antiguas colonias espaniolas, una vez conseguida la independencia, escogieron un camino cultural distinto del anterior. Al apartarse del pasado de la colonia, que representaba el pasado de la opresión, los nuevos estados iberoamericanos buscaron nuevas inspiración culturales en otros estados americanos. El afrancesamiento se dejó sentir en el plano artístico en toda América, negando los siglos de historia y recogiendo prestamos culturales de otros países europeos - Francia ${ }^{18}$, Inglaterra y Estados Unidos, primordialmente- Como señaló Rodríguez Prampolini: "las primeras generaciones del siglo XIX se encontraron improvisadamente con la responsabilidad de formar una nación. Existía, como es natural, una tradición, pero era la tradición odiada, la incómoda, la que había ocasionado el atraso en las colonias con respecto a los paises más adelantados de la tierra como eran los Estados Unidos, Inglaterra y Francia ... Hay que imitarlos, hay que desvincularse culturalmente de ellos y desprenderse de todo lo que ostente el sello español que lo odiado y lo atrasado" ". Y ciertamente el cosmopo- 
litismo postindependiente opinaba que la arquitectura y las bellas artes eran patrimonio exclusivo de Francia.

A tenor de las aspiraciones culturales cosmopolitas de la América independiente se frenó la llegada de obras plásticas procedentes de España, para favorecer los envíos franceses, ingleses o italianos, en un momento en el que la nueva burguesía comenzaba a valorar la posesión de obras de arte como un signo más de su nuevo status económico y social. En Buenos Aires el gobierno y los particulares gustaron de la pintura romántica y academicista francesa, los pensionados mejicanos o chilenos se trasladaban a París o Roma para recibir la formación docente oportuna a la par que nacían mecanismos de comercialización de obras de arte vinculados con el quehacer creativo de aquellos países europeos. Se ignoraron los logros de Goya y su generación, se infravaloró la plástica barroca peninsular, considerando al arte coetáneo como un periodo yermo en aspiraciones e innovaciones. En tal sentido afirmaba Lozano Mouján, para el caso argentino que "la cultura argentina es hija de Francia. La pintura y la escultura, y aún el gusto artístico de la ciudad, acusan esa misma procedencia" ${ }^{20}$.

Solamente a fines del siglo XIX y los primeros años del XX América se sintió parcialmente defraudada de su antigua pasión europeísta y volvió sus ojos hacia una cultura española redescubierta. En el campo de la literatura y el pensamiento Enrique Larreta (La gloria de Don Ramiro), Ricardo Rojas ( La Restauración Nacionalista), Vasconcelos (La Raza Cósmica), Ugarte (El porvenir de la América española), Gálvez (El solar de la Raza) o los peruanos Uriel García y Luis Valcárcel preconizaron un olvido del secular desprecio por lo español, para volver a encontrarse con la cultura peninsular, en ocasiones influidos por la búsqueda de la esencialidad hispánica emanada de la Generación del 98. Este movimiento cultural que pudiera llamarse "hispanófilo" cuajó en importantes sectores de la sociedad civil americana, especialmente en las capas urbanas de las principales capitales. Esta variable, unida al peso de la emigración española en algunos países como Argentina, determinaron un creciente interés por las manifestaciones artísticas de signo peninsular.

En arquitectura la obra teórica de Ricardo Rojas en Argentina cuajó en el denominado "spanish style" ${ }^{21}$ en las realizaciones de Noël y en edificios como el Banco de Boston de Buenos Aires (con rasgos copiados de San Marcos de León) y el Hospital de la Santa Cruz de Toledo) o el Teatro Cervantes, copia prácticamente literal de la fachada de la Universidad de Alcalá de Henares. En Méjico también existió una vertiente constructiva relacionada con lo hispánico, como se atestiguó por ejemplo con el pabellón presentado en la Exposición Universal de París de 1900, inspirado en modelos moriscos. 
En lo referente a las artes plásticas la influencia peninsular en toda Iberoamérica a partir del último tercio del pasado siglo es incontestable. La reincorporación del arte español vino de la mano de una cultura en proceso de definición que cuando quería encontrar sus raíces estaba obligada a apoyarse en la presión de su pasado hispánico y en la herencia indígena. No es casual que el coleccionismo de esas fechas se orientase precisamente hacia los objetos precolombinos y hacia la pintura española, que llegaba a ultramar en no pocos lotes remitidos periódicamente.

Un nuevo coleccionismo artístico nació entonces en la América de habla española, coincidiendo con el gusto por la "españolada" general en varios países europeos (principalmente Inglaterra y Francia) y Estados Unidos. El auge de la "españolada se señaló con la exposición y venta de "La Vicaría" de Fortuny en 1870 en una prestigiosa galería francesa ${ }^{22}$. Así la llegada abrumadora de productos pictóricos o escultóricos españoles coincide en firmas y estilo con las tendencias favoritas del mercado internacional. La pintura de casacón, el paisaje, la escena de costumbres y el retrato elaborado mediante fotografías fueron los géneros exigidos en el reciente mercado americano.

La llegada de obras de arte peninsulares a la Iberoamérica se hizo posible gracias a la existencia de mecanismos de comercialización artística "modernos": galerías, marchantes, coleccionistas y críticos, que superaban el proceso de encargo directo habitual en la colonia. Todos los países iberoamericanos, en función a la presión de las capas burguesas de la sociedad más o menos mayoritarias, se integraron en las modernas redes del comercio de arte internacional.

En Argentina la creación de la galería Witcomb a fines del siglo XIX, a la que sucederían negocios expositivos como Castillo o Costa; la sede de $E l$ Diario de la Marina o la Cámara de Comercio Española en La Habana, y los clubes españoles en Méjico y Chile mostraron al público americano periódicos lotes de pintura española, remitida a ultramar por la labor, a veces oscura de marchantes de idéntica nacionalidad. Artal en Buenos Aires, Bou en toda América del Sur, Pinelo en los países del cono sur e industriales como Menéndez o periodistas como el director del habanero Diario de la Marina encontraron en casi todo el continente un poderoso mercado que progresivamente requería objetos artísticos de firma peninsular. Se generalizó así un coleccionismo de arte español integrado generalmente por clientes de idéntica procedencia nacional debido en parte al peso cultural de la migración peninsular, $y$ al auge en la consideración de nuestra plástica.

Las consecuencias directas de la gestación de semejante mercado americano fueron una progresiva demanda de cuadros y esculturas para particu- 
lares e instituciones oficiales, la radicación de artistas en aquellos países y, sobre todo, la modificación de los viajes de estudio a Europa de los creadores americanos de París o Roma a España. Y es que en cierta medida después de la independencia la historia del arte iberoamericano está imbricada con la española, de la misma forma que no es posible conocer la trayectoria de nuestro desarrollo artístico sin recurrir al análisis de la presencia y correspondencia con América. Sin duda, las interacciones en el campo artístico entre la península y el continente americano constituye un capítulo más del episodio general de correspondencias mutuas con toda Iberoamérica.

\section{NOTAS}

1 El proyecto de Gil fue secundado por el Director de la Casa de Moneda, José Mangino y por el Virrey Martín de Mayorga, además de miembros de la sociedad civil. Uribe, E., $Y$ todo .. por una nación. Historia de la producción plástica en la Ciudad de Mexico. 1761-1910, México, 1984, p. 19-21.

2 Moyssén, X., El pintor Rafael Ximeno Planes. Su libreta de dibujos, México, 1985.

3 Angulo friiguez, D., "La Academia de Bellas Artes de Méjico y sus pinturas españolas", Arte de America y Filipinas, cuaderno I, Sevilla, 1935.

4 Los avatares del proceso de creación y sostenimiento del colegio de becados mejicanos en Madrid está recogido en García Sáiz, M. C. y Rodríguez Tembleque, C., "Historia de un intento fallido: la Academia madrileña para pensionados mexicanos", Cuadernos de Arte Colonial no 2, Madrid, 1987, pp. 5-17.

5 Los dos arquitectos espafioles eran Gervasio de Palacio y José Ramón Cuevas, ex-alumnos de San Fernando. Fundamentaron su propuesta en la necesidad de formar cuerpos técnicos instruidos teóricamente pues en la práctica las obras caían en manos de maestros de obras con escasa o nula instrucción. Libro de Actas, Juntas ordinarias, extraordinarias, generales y públicas 1839-1948, Archivo de la Academia de San Fernando, Leg. 3/90.

6 Precisamente en la última década del siglo XVIII la construcción de la catedral de Cuba originó un conflicto de competencias con San Fernando, por considerar la Academia que los planos remitidos por ingenieros militares establecidos en la isla eran "indignos e incorrectos de servir a una obra tan dispendiosa y tan propia de su clase". Comisión de Arquitectura. Informes 1788-1797, Leg. 128-1. Archivo de la Academia de San Fernando de Madrid. Al final la Academia propuso a Manuel Martín Rodríguez para la realización del proyecto frente a la pretensiones cubanas.

7 La contratación de Clavé fue inusitadamente irregular pues en la cátedra de pintura habla sido seleccionado Eugenio Anieni, aunque varios políticos conservadores del momento consideraron que Clavé reunía "poderosas razones" para ocupar el cargo. Como ha sefialado Esther Acevedo Clavé era católico, hablaba español y se identificaba con la corriente nazarena que aportaba al arte valores religiosos, lo cual agradaba entonces a los grupos de presión mejicana. Acevedo, E., "El patrocinio de la Academia de San Carlos y la producción pictórica. 1843-1857", Las Academias de Arte, México, 1985, pp. 87-123.

8 Como ha senialado Ana Helfant "desde el punto de vista estético de la historia de la pintura chilena, la Generación del 13 puede ser considerada como un paréntesis. Álvarez de Sotomayor introdujo el interés por al pintura de figuras más que por el paisaje y una variación en el uso de 
los colores, como por ejemplo, el negro, frecuente en la pintura espafiola". Helfant, A., "Los pintores de medio siglo en Chile", Panorama de la pintura Chilena, tomo II, Santiago, 1985, p. 67.

9 "La gestión de Sotomayor resultó ser muy fecunda. Hoy todavía se habla de la "época de Sotomayor", queriendo graficar con ello la etapa de su permanencia en Chile, perlodo en el cual la pintura nacional se ubicó bajo el alero de la tradición artística española, sustituyendo con ello el persistente influjo francés que habla sido característico en el arte nacional a lo largo del siglo XIX y principios del actual". Zamorano Pérez, P. E., "Fernando Álvarez de Sotomayor y la pintura chilena". Revista Universum, Universidad de Talca, 1989, p. 20.

10 Catálogo Salón Nacionah Santiago de Chile, 1943.

11 Catalogo de la Primera Exposición Humoristica de América del Sud Buenos Aires, 1896. Biblioteca Nacional de Buenos Aires. En esta muestra se prohibía entrar "a los non natos, a los tontos de solemnidad, a los que tengan el feo vicio de dejar su sombra en la puerta, a los que no sepan de memoria su nombre y apellidos y a los que quieran entrar en bicicleta".

12 Mendieta, Fray J. de, Historia Eclesidstica Indiana, México, 1966, pp. 249-250.

13 En este sentido el pintor zaragozana Victoriano Balasanz responsabilizaba de su traslado a Uruguay "a la espera de una mejor fortuna para acabar alli mis días con la misma laboriosidad que aqui" García Guatas, M., "Victoriano Balasanz o la frustración de ser pintor en Zaragoza", Seminario de Arte Aragones, Zaragoza, 1991, p. 334.

14 Los retratos de Manuel Valle Fernández y Jovellanos, realizados respectivamente por Dionisio Fierros y Ventura Álvarez Sala, deberian haber sido el origen de una iconoteca de personajes ilustres asturianos que no llegó a terminarse.

15 Barros, G., "La caricatura en Cuba", Cuba Contempordnea, Afio II, tomo V, no 3, La Habana, julio de 1914, p. 315.

16 En 1905 el crítico de la revissa Papel y Tinta exclamaba al respecto: "Los dibujantes espafioles son legión hoy en Buenos Aires", "Artistas españoles", Papely Tinta, Año II, $\mathrm{n}^{\circ}$ 38, Buenos Aires, 30 de abril de 1908, p. 3.

17 Para la sede la colectividad asturiana en la capital habanera realizó dos grandes escenas: una la del mítico Pelayo en Covadonga y otra una alegoria de Asturias. El Libro del Centro Asturiano de La Habana 1886-1927, La Habana, 1928.

18 En el caso mejicano, la influencia de la cultura y el arte francés vino de la mano de la monarquía de Maximiliano, pues con él llegaron pintores, arquitectos y fotógrafos, algunos de ellos relevantes, como el pintor de batallas Jean Adolphe Beaucé. Acevedo, E., "Documentación de la época del segundo imperio", Memoria del Museo Nacional de Arte, n 3, México, 1991, pp. 43-57.

19 Rodríguez Pampolini, I., La critica de arte en México en el siglo XIX, México, 1964.

Lozano Mouján, J. M., Figuras del arte argentino, Buenos Aires, 1928, p. 22.

Gutiérrez, R., Arquitectura y urbanismo en Iberoamérica, Madrid, 1983, p. 561.

Otros hitos relativos al aprecio del arte espafiol por parte de los artistas y críticos francese fue la apertura del Museo Espaniol Luis Felipe en 1838, que en su día fue la más extensa colección de arte peninsular fuera de Espahia, la presencia de viajeros franceses en el país y el interés demostrado por los grandes genios del siglo de oro por parte de creadores galos del ochocientos. Haskell, F., Redicoveries in Art. Some aspects of taste, fashion and collecting in England and France, Oxford, 1976. 